Editorial

\title{
La fiebre amarilla, una amenaza latente a la salud pública global
}

Desde el siglo XVIII hasta principios del siglo XX, la Fiebre Amarilla (FA), fue un problema de alto impacto en la salud pública, principalmente, en países de África y Latinoamérica; en la actualidad, la FA es una amenaza latente a la salud global. El virus de la FA fue introducido al continente americano desde África occidental hace, aproximadamente, 400 años con el comercio de esclavos y se adaptó de manera rápida a los nuevos nichos ecológicos, hospederos susceptibles y vectores.

En 1881 en Washington D.C., el Dr. Carlos J. Finlay (Cuba 1833-1915), propuso que la FA era transmitida al hombre por la picadura del mosquito Aedes aegypti; a pesar de que su aseveración fue recibida con reservas, más tarde, la Comisión de la Armada de los Estados Unidos de América para el estudio de la FA, confirmó la hipótesis del Dr. Finlay; este hallazgo permitió fortalecer las intervenciones para el control de los mosquitos, que tuvieron gran impacto en la morbilidad y mortalidad de la FA en países y regiones endémicas (1).

La FA, también conocida como "vómito negro", es la fiebre hemorrágica prototipo, la cual es causada por el virus de la (Familia Flaviviridae, género flavivirus) y es transmitida al hombre por la picadura de mosquitos, principalmente, Aedes aegypti (FA urbana). La enfermedad tiene dos ciclos, el selvático y el urbano, siendo el primero el que persiste en zonas endémicas y asociado a la mayoría de los casos reportados; los huéspedes son primates no humanos y los mosquitos vectores son de los géneros Haemagogus y Sabethes (FA selvática).
En la actualidad, aproximadamente, mil millones de personas, de 49 países endémicos, están en riesgo de adquirir la infección. Desde 2016 y hasta el presente, Brasil, ha reportado cerca de dos mil casos de FA, de los cuales 574 se han confirmado y se presentaron 282 casos fatales. Considerando que Brasil tiene frontera con 10 países con las condiciones para la transmisión del virus, es un riesgo latente para la aparición de casos de origen selvático y urbano en una amplia región de América del Sur (2). En este mismo período, otros países como Angola, China, Kenia, Chad, Ghana, Guinea, Congo y Surinam, han reportado casos de $\mathrm{FA}$. Al principio del siglo XXI, se notificó la circulación del virus de la FA en Brasil, Paraguay, Argentina, Colombia y Perú. En Brasil, durante 2008 se reportaron más de 200 focos epizoóticos de FA.

La iniciativa de la Organización Mundial de la Salud (OMS) contra la FA, establecida en 2006, en África Occidental, a través de la vacunación de 150 millones de personas, ha tenido un impacto positivo en la disminución de casos. Se estima que, en África, durante 2013, se reportaron entre 84,000 a 170,000 casos graves y 29,000 a 60,000 casos fatales atribuibles a la FA; sin embargo, desde 2015, no se han reportado brotes en esta región. Las epidemias de FA son más comunes en África Occidental, que en el resto del Continente Africano y se desconocen las causas de este comportamiento (3). Es interesante resaltar que la FA no es endémica en países asiáticos, a pesar de que son comunes otras enfermedades virales transmitidas por los mosquitos Aedes aegypti.

Este documento está disponible en https://doi.org/10.32776/revbiomed.v28i3.585

Copyright (c) 2017 por autores (s) y Revista Biomédica.

Este trabajo esta licenciado bajo las atribuciones de la Creative Commons (CC BY).

http://creativecommons.org/licenses/by/4.0/

Fecha de publicación: 1 de septiembre de 2017 
Ramos, et al

Algunos factores de riesgo asociados con la aparición y dispersión de la FA, son la introducción del virus en zonas ampliamente pobladas, la alta densidad de mosquitos, la escasa o nula inmunidad de la población, la falta de vacunación y los problemas para el control de los mosquitos. Pruebas realizadas con la especie Alouatta sp, fueron altamente susceptibles a la infección por el virus de la FA, lo cual resultó de utilidad para la vigilancia epidemiológica, ya que las epizootias que ocurren en estos animales, son una alerta para prevenir casos en humanos.

Las personas infectadas pueden ser asintomáticas y los sintomáticos suelen presentar fiebre, cefalea, ictericia, mialgias, náusea, vómito, cansancio y pérdida del apetito. Los casos agudos presentan hepatitis, falla renal, fiebre, ictericia, dolor abdominal, vómito, hemorragias y choque hipovolémico entre 20 y $60 \%$ de los casos. Algunas manifestaciones pueden confundirse con paludismo grave, leptospirosis, hepatitis virales, dengue grave, intoxicaciones y otras fiebres hemorrágicas, por lo que es necesario realizar el diagnóstico diferencial para establecer el tratamiento adecuado y oportuno (4). En un estudio reciente de pacientes con síndrome de fiebre hemorrágica viral y hepatitis, realizado en diversos hospitales de Ghana, región donde se han reportado casos de FA, ninguno de los casos fueron confirmados como tal.

El diagnóstico de la FA en la fase aguda se puede hacer mediante la detección de anticuerpos o del genoma del virus por técnicas moleculares. La técnica de ELISA para detectar IgM contra el virus tiene el inconveniente de tener reacciones cruzadas con anticuerpos que reconocen otros flavivirus, como el dengue; por otro lado, algunos pacientes con dengue severo presentan un cuadro clínico similar a la FA, por lo que es importante tener las herramientas clínicas, epidemiológicas y de laboratorio para hacer el diagnóstico diferencial en regiones donde hay circulación de diversos flavivirus. Las técnicas moleculares, como la RT-
PCR, pueden ser útiles por su alta sensibilidad y especificidad; aunque, recientemente, se han desarrollado otras técnicas moleculares, éstas aún no se utilizan para el diagnóstico y estudios epidemiológicos, sin embargo, pueden contribuir para el análisis presuntivo en áreas endémicas remotas. El aislamiento del virus es de utilidad para estudios de virulencia y de transmisión en mosquitos, pero, su uso es limitado por razones de bioseguridad.

El descubrimiento, en 1937, de la vacuna viva atenuada contra la FA (17D), por el grupo de Max Theiler (Fundación Rockefeller y Premio Nobel de Medicina en 1951) y, posterior aplicación, coadyuvó a controlar la enfermedad en zonas endémicas. Actualmente, existen dos vacunas, 17DD y 17D-204, elaboradas por seis compañías farmacéuticas, cuya eficacia de protección es similar y de las que se produce entre 80 y 90 millones de dosis al año, con una reserva mundial de 6 millones de dosis anuales para casos de emergencias. Brasil, produce la vacuna 17DD y los otros cinco fabricantes, la 17D-204. Los efectos adversos asociados a la vacunación son mínimos y quienes no deben vacunarse son los niños menores de nueve meses de edad, excepto durante las epidemias donde se debe vacunar a los niños de 6 a 9 meses de edad, en zonas de alto riesgo, mujeres embarazadas, excepto durante los brotes con alto riesgo de infección, personas alérgicas a proteínas del huevo y personas inmunodeprimidas. La vacuna 17D tiene riesgos, ya que, se han reportado algunos casos de afectación visceral y neurológica después de la vacunación. Debido a la eficacia de las vacunas disponibles no se recomienda la re-vacunación, salvo en casos particulares, como en las personas que fueron inmunizadas en la infancia y que radican en zonas endémicas o en situaciones de epidemias. De acuerdo a las regulaciones sanitarias internacionales, se recomienda la revacunación en viajeros internacionales, después de 10 años de haber sido vacunados; del mismo 
La fiebre amarilla, una amenaza latente

modo, esta recomendación puede ser aplicable a los trabajadores ocupacionalmente expuestos $(5,6)$. Ante la creciente demanda de vacunas, se puede aplicar dosis parciales, es decir, en vez de inyectar $0.5 \mathrm{ml}$. se puede usar $0.1 \mathrm{ml}$. con una eficacia protectora similar.

No existe un procedimiento específico para casos de FA, sin embargo, la administración de interferón alfa y anticuerpos contra el virus, pueden ser de utilidad como medida profiláctica en las personas infectadas, el inconveniente es que, para una mejor efectividad, el tratamiento debe administrarse poco tiempo después de la infección. Otras moléculas, como el RNAi y la Ribavirina, no han mostrado buena efectividad, aunque, se encuentran en proceso de evaluación otros medicamentos.

Las estrategias de la OMS para controlar los brotes de FA, incluyen la vigilancia y evaluación de riesgos, la vacunación, la gestión de casos, la movilización social y comunicación de riesgos, y la lucha anti-vectorial. Algunas de las actividades prioritarias para la vigilancia epidemiológica de la FA comprenden la vigilancia en zonas no endémicas, con riesgo de introducción del virus, la vacunación en grupos de riesgo, la disponibilidad suficiente de la vacuna para casos de emergencias, el desarrollo de nuevas vacunas (inactivadas y/o recombinantes), el mejoramiento de los métodos de diagnóstico y el mejoramiento de los tratamientos específicos y de apoyo.

No hay duda de que la FA, es una amenaza latente para amplias regiones del mundo $\mathrm{y}$ que, además de las acciones mencionadas, es importante difundir información sobre la enfermedad a los profesionales de la salud, a los académicos, a los responsables de las políticas en salud, a las empresas farmacéuticas y a la población en general.

Dr. Celso Ramos

Instituto Nacional de Salud Pública

Cuernavaca, Morelos

\section{REFERENCIAS}

1. Ferreira-Morena V. Evocation to the Dr. Carlos J. Finlay Barres on the centennial of his death. Colomb Med. 2016 Ene-Mar; 47(1): 63.-66.

2. Ortiz-Martinez Y, Patiño-Barbosa AM, RodriguezMorales AJ. Yellow fever in the Americas: the growing concern about new epidemics. F100Research. 2017 Apr; 6: 398. doi: 10.12688/f1000research.11280.2. eCollection 2017.

3. World Health Organization. Yellow fever surveillance and outbreak response: revision of case definitions. October 2010. Wkly Epidemiol Rec. 2010 Nov; 85: 465. http://www.who.int/wer/2010/wer8547. pdf?ua $=1$

4. Monath TP, Vasconcelos PFC. Yellow Fever. J Clin Virol. 2015 Oct; 64(1):160.-173.

5. Barret AD. Yellow fever live attenuated vaccine: a very successful live attenuated vaccine but still we have problems controlling the disease. Vaccine, 2017. In Press, DOI: 10.1016/j.

6. Barnett ED, Wilder-Smith A, Wilson ME. Yellow fever vaccines and international travelers. J Expert Rev Vaccines 2014 Jan; 7(5): 579-87. 